\title{
CONCEPÇÕES DE PROFESSORES UNIVERSITÁRIOS SOBRE INOVAÇÃO PEDAGógICA
}

\author{
CONCEPTIONS OF PROFESSOR ABOUT INNOVATIVE \\ PEDAGOGICAL PRACTICES
}

\section{CONCEPCIONES DE DOCENTES CON RESPECTO A}

PRÁCTICAS PEDAGÓGICAS INNOVADORAS

\section{Raul Araújo ${ }^{1}$ \\ Rosalie Belian ${ }^{2}$}

RESUMO: Este trabalho apresenta resultados de uma pesquisa que objetivou compreender as concepções de docentes sobre práticas pedagógicas inovadoras em uma instituição de ensino superior, tendo como questão norteadora: o que os docentes compreendem por prática pedagógica inovadora no ensino superior? Empregou-se um estudo descritivo, com abordagem qualitativa, realizada com 206 docentes da Universidade Federal de Pernambuco. A análise dos dados baseou-se na técnica do Discurso do Sujeito Coletivo. Observou-se que nesta instituição há um caminho traçado para inovação pedagógica no ensino superior, que precisa ser fortalecido e sempre discutido, por todos os que participam do processo de ensino e aprendizagem, acreditando na continuidade e na permanente inovação.

PALAVRAS-ChAVE: Ensino superior. Métodos didático-pedagógicos. Prática pedagógica.

ABSTRACT: This paper presents the results of a research that aimed to understand the teachers views about innovative pedagogical practices in a Higher Education Institution. Its research question was 'What do Teachers understand by Innovative Pedagogical Practices in Higher Education?' We have used a descriptive study, with a qualitative approach, with 206 teachers of the Federal University of Pernambuco. Data was analysed with the Collective Subject Analysis Discourse technique. We have observed that in this institution there is a path to pedagogical innovation in higher education that needs to be strengthened and discussed by all that participate in the teaching-learning processes, so that there can be continuity and permanent innovation.

KEYWORDS: Higher education. Methods didactic pedagogics. Pedagogical practice.

RESUMEN: Este trabajo presenta los resultados de una pesquisa que tenía el objetivo de comprender las concepciones de docentes con respecto a prácticas pedagógicas innovadoras en una institución de enseñanza superior, tuvo como cuestión norteadora: o que los docentes comprenden por prácticas pedagógicas innovadoras en enseñanza superior? Se empleó un estudio descriptivo, con abordaje cualitativo, realizada con 206 docentes de la "Universidade Federal de Pernambuco". El análisis de los datos se ha basado en técnica de "Discurso del Sujeto Colectivo". Lo que se observó fue que en la institución existe un camino que ya está marcado para la innovación pedagógica en la enseñanza superior, que necesita ser fortalecido y siempre discutido, por todos los que participan en el proceso de enseñanza y aprendizaje, creyendo en la continuidad e innovación permanente.

PALABRAS ClaVE: Enseñanza superior. Métodos didáctico-pedagógicos. Práctica pedagógica.

Submetido em: 11/02/2018 - Aceito em: 31/03/2018 - Publicado em: 04/04/2018

\begin{tabular}{|l|c|c|c|c|c|}
\hline (C) Rev. Inter. Educ. Sup. & Campinas, SP & v.4 & n.2 & p.387-400 & maio/ago. 2018 \\
\hline
\end{tabular}




\section{INTRODUÇÃO}

A sociedade do conhecimento, assim denominada por seu desenvolvimento convergente com as tecnologias da informação e da comunicação criadas no século XX, vem exigindo novas formas de pensar o ensino e a aprendizagem na educação superior. Desse modo, o processo de ensino e aprendizagem baseado em método e técnicas tradicionais, assentado no saber e na ação do educador, vem sendo repensado, a partir de práticas direcionadas à aprendizagem do educando e seu desenvolvimento pessoal (BEHRENS, 2005; LÉVY, 2010).

No contexto da educação superior, o repensar e reestruturação do processo de ensino e aprendizagem vem sendo denominada por alguns autores de inovação pedagógica, podendo também ser considerada como uma mudança paradigmática, sendo caracterizada, a princípio, por uma ruptura conceitual, entre modelos pedagógicos conservadores e modelos pedagógicos emergentes de ensino e aprendizagem (BEHRENS, 2005; MASETTO, 2012; MORAES, 2012).

Nesse sentido, consideram-se os modelos pedagógicos conservadores como baseados na transmissão e na memorização de informações, tendo como ator principal o educador, enquanto o educando seria um receptor passivo das informações transmitidas em sala de aula. Enquanto que os chamados modelos pedagógicos emergentes, buscariam um processo de ensino e aprendizagem horizontalizado entre educador e educando, para que ambos possam desenvolver habilidades como aprender a aprender, aprender a fazer e aprender a ser (DELORS et al., 1998; LEITE; ZABALZA, 2012; FREIRE, 2014).

Dessa maneira, o emprego dos supracitados modelos pedagógicos suscita questões epistemológicas sobre o ensino superior, ampliando também a discussão voltada à prática de novas formas de ensino e aprendizagem, que deveriam atender alguns aspectos, como: aplicação de métodos e técnicas de ensino inovadores; apoio à gestão participativa entre educadores e educandos; integração de diferentes saberes, como o saber popular e o saber científico; articulação entre teoria e prática, pensadas como indissociáveis; estímulo e desenvolvimento do protagonismo e da autonomia tanto de educandos, quanto de educadores (BEHRENS, 2005; MASETTO, 2012; MORAES, 2012; MORIN, 2013).

Nesse contexto, e diante da complexidade envolvida na concepção, planejamento, operacionalização, desenvolvimento e avaliação de inovações pedagógicas no ensino superior, e na importância do conhecimento e do reconhecimento dessas etapas para melhor execução e disseminação de propostas inovadoras, foi desenvolvida uma pesquisa com o objetivo de compreender as concepções de docentes sobre práticas pedagógicas inovadoras em uma instituição de ensino superior. $\mathrm{O}$ estudo teve a seguinte questão norteadora: o que os docentes compreendem por prática pedagógica inovadora no ensino superior?

\begin{tabular}{|l|l|l|l|l|l|}
\hline (C) Rev. Inter. Educ. Sup. & Campinas, SP & v.4 & n.2 & p.387-400 & maio/ago. 2018 \\
\hline
\end{tabular}


Assim, a compreensão dos docentes sobre uma prática pedagógica inovadora, bem como a discussão que emergirá a partir de seus relatos, poderá subsidiar a constituição de políticas de formação tanto de educadores, quanto de educandos. Além disso, pode se conformar como uma ferramenta imprescindível ao diálogo institucional sobre práticas pedagógicas inovadoras, e à dinamização do processo de ensino e aprendizagem no ensino superior.

\section{Educação superior e suas concepções}

As abordagens educacionais, assim como inúmeras áreas do conhecimento, sofreram influência do arcabouço teórico-metodológico construído pela ciência moderna, que se estruturou num pensamento lógico-matemático, na dicotomização entre sujeito e objeto, na disjunção e no reducionismo para explicação de fenômenos complexos, tendo como expoentes Copérnico, Newton e Descartes (KOYRÉ, 2010; SANTOS, 2011; MORIN, 2013).

Conforme Cunha (2008) e Behrens (2005), as abordagens educacionais passam por uma transição paradigmática, entre modelos pedagógicos tradicionais, denominados de forma geral de newtoniano-cartesiano, e modelos pedagógicos emergentes.

Os modelos pedagógicos tradicionais fundamentaram as práticas pedagógicas e curriculares nas universidades, baseando-se em um paradigma lógico-matemático, advindo com o desenvolvimento e estruturação da ciência moderna. Nessa perspectiva, a produção do saber assentou-se no conhecimento advindo de fatos testáveis, passível de generalizações, que caracterizou os conhecimentos não pautados em seus princípios e regras, como pseudociência ou metafísica (SANTOS, 2011; MORAES, 2012; MORAN; MASETTO; BEHRENS, 2013).

Desse modo, foram enfatizados os conhecimentos quantificáveis, reduzindo-se os fenômenos complexos em partes, para que sistematicamente fossem elaboradas relações entre os fragmentos, a fim de compreenderem-se os fenômenos, numa abordagem mecanicista, baseada no mundo-máquina (SANTOS, 2011), levando ao que Ludwik Fleck (2010) denominou de esoterização do conhecimento, por meio do desenvolvimento disjuntivo e superespecialização das ciências.

Os modelos pedagógicos tradicionais influenciaram o cenário educacional, e consequentemente, a produção do conhecimento, por se ancorar na divisão das totalidades em partes cada vez menores, a fim de compreender os fenômenos a serem estudados. Também houve a dicotomização entre sujeitos e objetos, seres e saberes, enfatizando-se a objetividade e a formalização do conhecimento, adotando-se a matemática como linguagem, em contrapartida da subjetividade envolvida na construção dos saberes (MORAES, 2012; MORAN; MASETTO; BEHRENS, 2013). 
Por outro lado, os modelos pedagógicos emergentes, que segundo Boaventura Santos (2010, 2011) originaram-se no reconhecimento de que o sujeito interfere no objeto observado, e que fragilidades no rigor da matemática e da medição foram expostas. Baseiam-se na pressuposição de que o conhecimento seja compreendido por meio da problematização das práticas pedagógicas que foram alicerçadas sobre os princípios da ciência moderna, promovendo uma ruptura com as formas tradicionais de ensinar e aprender, reconhecendo-se a existência de outras formas de produzir conhecimento, que relevam a historicidade, a inserção social e o protagonismo dos educandos, e reorganizam a relação entre teoria e prática, como condições para uma aprendizagem significativa.

A construção do conhecimento, e não apenas sua transmissão, conforme descrito por Edgar Morin $(2012,2013)$, assentar-se-ia na elaboração de um pensamento complexo, religando e contextualizando os saberes, para a compreensão de realidades multidimensionais, apesar do entendimento da impossibilidade de se adquirir a completude do saber.

Nesse sentido, a religação e a contextualização dos saberes têm sido enfatizadas na educação superior, devido à necessidade de múltiplos enfoques para a compreensão do conhecimento humano, referindo-se à interdisciplinaridade como forma de pôr em contato os diferentes saberes, a fim de enfrentar problemas relacionados à simplificação das abordagens educacionais (ALMEIDA et al., 2007).

Simplificação que de modo algum foi irrevelante, pois aliada ao determinismo para solução dos problemas na área da saúde, alcançou avanços substanciais, que ocasionaram o surgimento de inúmeras disciplinas e especialidades (CANGUILHEM, 2011; FOUCAULT, 2006; 2014).

Diante desse contexto, é que se tem buscado o fomento a discussões e pesquisas na educação superior sobre práticas pedagógicas inovadoras, que têm se ampliado cada vez mais (LEITE; ZABALZA, 2012). E um dos temas tratados é a introdução de Tecnologias da Informação e da Comunicação (TIC) no processo de ensino e aprendizagem, que podem viabilizar um maior acesso ao conhecimento, tendo o potencial de ir além da transmissão de informações, podendo auxiliar educadores e educandos na compreensão e integração de diferentes saberes (LÉVY, 2010; KENSKI, 2012).

As TIC, além de facilitar o acesso ao crescente universo do conhecimento, também podem ser aplicadas na mediação pedagógica no contexto da educação superior, apesar das dificuldades apresentadas na superação da transmissão de informações, ou seja, da utilização das TIC como meio de digitalizar modelos pedagógicos conservadores (MORAN; MASETTO; BEHRENS, 2013).

\begin{tabular}{|l|l|l|l|l|l|}
\hline (C) Rev. Inter. Educ. Sup. & Campinas, SP & v.4 & n.2 & p.387-400 & maio/ago. 2018 \\
\hline
\end{tabular}


Mesmo com tamanho desafio, as TIC têm um potencial a ser explorado na integração dos diversos saberes humanos, em uma questão que pode subsidiar a interdisciplinaridade. Também pode potencializar a articulação entre teoria e prática por meio de simulações, assim como facilitar o desenvolvimento da autonomia entre os alunos (KENSKI, 2012; MORAN; MASETTO; BEHRENS, 2013).

Todavia, o fator humano no processo de ensino e aprendizagem, apesar dos avanços tecnológicos, deve ser considerado. Ressalta-se nesse ponto, a importância do respeito aos conhecimentos trazidos pelos educandos e a possibilidade de resgatá-los, integrando-os às disciplinas formais da educação superior, em uma formação contextualizada à realidade dos educandos, e voltada à aprendizagem significativa (MORIN, 2013; MORAN; MASETTO; BEHRENS, 2013; FREIRE, 2014).

Dessa forma, a inovação pedagógica na educação superior poderia colaborar com a disposição dos educandos em aprender, e em tornar o conteúdo significativo para cada um dos educandos a aprendê-lo, convergindo para uma aprendizagem significativa. Além disso, tem o potencial para formação de cidadãos críticos, criativos e reflexivos, que fazem parte de uma sociedade que está em constante transformação e mudança (MASETTO, 2012). Nesse sentido, também se destaca a inclusão dos educandos na esfera de tomada de decisões em relação ao seu processo de formação (MORAN; MASETTO; BEHRENS, 2013).

Essa inclusão, também conhecida como gestão participativa, torna a relação entre educador e educando mais horizontal, diferentemente de modelos pedagógicos mais conservadores, onde o educador toma as decisões, repassando-as aos educandos. A gestão participativa envolveria os educandos desde a concepção até a avaliação do processo de ensino e aprendizagem, tornando-os corresponsáveis na formulação de inovações pedagógicas (MORAN; MASETTO; BEHRENS, 2013).

Desse modo, a construção de uma inovação pedagógica na educação superior coloca educadores e educandos como autores e corresponsáveis. Essa relação possibilita ao educando, sair da condição de receptor dos conhecimentos transmitidos, para ser ativo, buscar seu conhecimento, autonomia e liberdade para criar seu próprio caminho em busca de uma aprendizagem profunda e significativa (FREIRE, 2014).

No entanto, uma mudança de pensamento e postura pedagógica, diante de práticas docentes inovadoras, constitui-se em um desafio para a realidade educacional no ensino superior. Essa mudança de prática pedagógica que destacamos aqui, desafiadora e reflexiva, a fim de superar a mera transmissão de informações, defronta-se com um dos segmentos educacionais mais cristalizados, "fortes e estáveis" na sociedade, que segundo Dias Sobrinho (2005) é a educação superior. 
Trata-se, portanto, de uma quebra de modelo e de pensamento, não somente do ensino e da aprendizagem, mas da própria concepção de universidade e de seu papel, sedimentada há séculos na sociedade e no cenário educacional, como um segmento produtor e detentor de conhecimentos, que pouco se articulou às mudanças estruturais no processo de ensino ao longo dos anos (LEITE; ZABALZA, 2012; MASETTO, 2012).

\section{CAMINHAR METODOLÓGICO}

Esta é uma pesquisa descritiva, com abordagem qualitativa (CRESWELL, 2014), realizada com docentes da Universidade Federal de Pernambuco (UFPE), que é uma Instituição de Ensino Superior (IES) pública, localizada no Estado de Pernambuco, região nordeste do Brasil. A UFPE possui sedes nas cidades de Recife (administração central), Vitória de Santo Antão e Caruaru.

Os dados deste estudo foram coletados entre junho e julho de 2014 por meio de um instrumento online, enviado aos docentes em exercício na UFPE, aproximadamente 2.200 docentes. Desse total, obtiveram-se respostas de 206 docentes, cujas informações coletadas foram analisadas individualmente.

Dentre as informações coletadas constaram: disciplinas ministradas; departamento ao qual o docente estava vinculado; seu entendimento sobre o que caracteriza uma prática pedagógica inovadora; e se o docente realizava alguma prática inovadora, descrevendo a mesma.

A análise dos dados baseou-se na técnica do Discurso do Sujeito Coletivo (DSC), que foi desenvolvida no Brasil, em meados dos anos 1990, por Lefèvre e Lefèvre (2005).

O DSC apoia-se epistemologicamente na Teoria da Representação Social, sendo uma técnica de análise qualitativa, que sintetiza discursos semelhantes, por meio da sistematização e padronização dos valores, crenças e representações de uma coletividade, permitindo aos pesquisadores a compreensão de uma opinião desta coletividade (LEFÈVRE; LEFÈVRE, 2005).

Dessa maneira, o processo de análise teve início com a identificação dos sujeitos pesquisados pela letra "P" mais número de ordenamento, em uma alusão a professor. Com vistas a minimizar a margem de erros, no tocante à interpretação, após uma primeira leitura dos dados, foram definidos os discursos sínteses e divididos os resultados entre os participantes do grupo de pesquisa para análise. Em seguida, os dados analisados foram reavaliados e as dúvidas de categorização discutidas e esclarecidas por todo o grupo.

\begin{tabular}{l|l|l|l|l|}
\hline (c) Rev. Inter. Educ. Sup. & Campinas, SP & v.4 & n.2 & p.387-400
\end{tabular}

maio/ago. 2018


A análise dos dados ocorreu a partir das respostas de cada um dos docentes. Em cada uma das respostas buscamos identificar expressões-chave e ideias centrais, agrupando-as conforme foram emergindo semelhanças e ancoragens, a fim de se construir os discursos sínteses, que expressaram a compreensão da coletividade sobre inovação pedagógica.

O discurso dos participantes deste estudo foi destacado em itálico, sendo redigido na primeira pessoa do singular, de modo a expressar o pensamento compartilhado social e coletivamente.

\section{RESULTADOS}

Inicialmente, procedeu-se a tabulação dos discursos sínteses, agrupados a partir das expressões-chave e ideias centrais identificadas, além de suas respectivas ancoragens. Dentre as respostas dos 206 docentes, emergiram cinco discursos sínteses, distribuídos conforme o Quadro 1.

Quadro 1. Distribuição dos discursos sínteses

\begin{tabular}{|l|c|}
\hline \multicolumn{1}{|c|}{ Discursos sínteses } & Frequência \\
\hline Métodos e técnicas de ensino que estimulem a aprendizagem & $53,59 \%$ \\
\hline Tecnologias da informação e da comunicação mediando a prática pedagógica & $12,41 \%$ \\
\hline O compartilhar de saberes e vivências entre docentes e discentes & $12,41 \%$ \\
\hline Integração entre teoria e prática & $12,41 \%$ \\
\hline O aluno como protagonista da prática pedagógica & $9,15 \%$ \\
\hline
\end{tabular}

Fonte: Os autores.

Analisando o Quadro 1, constata-se que 53,59\% dos docentes pesquisados referem-se à inovação pedagógica como aplicação de métodos e técnicas de ensino, que estimulem a aprendizagem dos alunos, e situando-os como centro do processo de ensino e aprendizagem, em contrapartida do docente como detentor do saber.

Mesmo utilizando uma expressão tradicional para o sentido da prática (métodos e técnicas), o professor destaca isso a favor da aprendizagem. Ou seja, desloca o centro do processo educativo do professor, para a aprendizagem do aluno. Isto leva a crer, que no meio pesquisado, vem ocorrendo uma ruptura com modelos conservadores de ensinar e aprender.

Tal ruptura estaria sendo baseada em metodologias ativas, e desse modo, constituindo-se em um marco conceitual e metodológico na transição entre uma concepção conservadora e uma concepção inovadora (CUNHA, 2008). 
Outrossim, ao observar-se o discurso com a maior e o com a menor frequência, nota-se certa incoerência. Pois os alunos estariam sendo estimulados em sua aprendizagem, entretanto, poucos seriam vistos como protagonistas no processo de ensino e aprendizagem.

A seguir, encontram-se os cinco discursos sínteses, categorizados conforme o Quadro 1, além de suas respectivas discussões.

\section{Métodos e técnicas de ensino que estimulem a aprendizagem}

Nas discussões acerca das concepções sobre a inovação, um novo olhar se descortina. O docente passa a colaborar com os alunos na construção do conhecimento, e não mais a ser o detentor e o transmissor de saberes. Enquanto os alunos passam a ser o centro do processo de ensino e aprendizagem, apesar da relevância inegável de docentes e conteúdos a serem aprendidos (MASETTO, 2012).

Neste novo cenário, a intenção é que o docente assuma um papel de facilitador do processo de ensino e aprendizagem, incentivando nos alunos o desenvolvimento e consolidação de autonomia na construção do conhecimento (FREIRE, 2014).

Nesse discurso, observa-se o paralelismo traçado pelos professores entre novos métodos de ensino e o estímulo aos alunos. Desse modo, as concepções sobre inovação pedagógica estariam atreladas às novidades em termos de didática e estratégias de aprendizagem, tendo como fim, incentivar o corpo discente nas atividades educativas. Entretanto, a relação alunoaluno não foi comentada como ferramenta no processo de aprendizagem.

O estímulo e o incentivo aos alunos, conforme Masetto (2012), constituem-se na base da mediação pedagógica, em uma horizontalização da relação entre alunos e professores, plasmando o processo de ensino e aprendizagem a partir de pressupostos colaborativos, o que poderia incluir a relação entre os alunos, como um fator considerável na aprendizagem dos indivíduos.

As atividades colaborativas entre alunos-alunos e alunos-professores podem se assentar em uma relação dialógica, superando modelos conservadores de ensino, nos quais o professor é a fonte de saber, enquanto os estudantes são tábulas rasas, prontos a receber o conhecimento vindo do professor, o que caracterizaria o ensino bancário, de acordo com Freire (2014). 
Tecnologias da informação e da comunicação mediando à prática pedagógica

A introdução de novas tecnologias digitais em sala de aula é considerada como um recurso diferenciador para a prática docente e também como um estímulo ao aprendizado do discente, podendo proporcionar novas formas de ensinar e aprender, inseridas no paradigma educacional emergente, atendendo a demanda por uma construção do conhecimento que não se fundamente apenas na transmissão de informações e na memorização, e sim na compreensão dessas informações (KENSKI, 2012; SALES; LEAL, 2018).

No entanto, não se trata apenas de inseri-las no contexto educativo. É preciso aliar a inserção das tecnologias com uma nova prática de ensino. Lévy (2010) relata a importância da inclusão de ferramentas advindas da informática no processo de ensino e aprendizagem, a partir do embasamento de teorias da educação, evitando, dessa forma, a simples digitalização de métodos conservadores de ensino.

Portanto, como afirma Kenski (2012), as novas tecnologias precisam ser compreendidas e incorporadas pedagogicamente, respeitando as especificidades do ensino e da própria tecnologia. Para tanto, é necessário que os professores se apropriem do uso de novas tecnologias digitais, para uso pedagógico em sala de aula, buscando compreender seu real papel na aprendizagem do aluno, ultrapassando uma visão simplesmente motivadora, para outra problematizadora de aprendizagens profundas e significativas.

Desse modo, as tecnologias podem ser incluídas no processo de ensino e aprendizagem, adequando a formação acadêmica ao contexto da sociedade do conhecimento, que emergiu a partir da evolução tecnológica. Tendo como finalidade estimular a criatividade, contribuir para a formação de espírito crítico e para a autonomia dos alunos, além de serem facilitadoras na interação entre os alunos, e destes com os professores.

\section{O compartilhar de saberes e vivências entre docentes e discentes}

Tendo em vista uma concepção conservadora do ensino, o aluno era tido como um ser sem luz, uma folha em branco, prestes a absorver tudo o que o professor tinha para lhe repassar. $\mathrm{O}$ movimento que se percebe hoje está relacionado com uma troca de saberes, de compartilhamento e a construção coletiva entre docentes e discentes (MASETTO, 2012).

Nesse cenário, os docentes respeitariam o conhecimento e a experiência dos discentes. Freinet (2004) e Freire (2014) discutiram amplamente como os conhecimentos prévios dos alunos podem ser considerados em sala de aula e contribuir para a construção do saber.

\begin{tabular}{|l|c|c|c|c|c|}
\hline (C) Rev. Inter. Educ. Sup. & Campinas, SP & v.4 & n.2 & p.387-400 & maio/ago. 2018 \\
\hline
\end{tabular}


Assim, o resgate dos conhecimentos prévios dos alunos representa item essencial na construção do conhecimento, e não apenas em sua transmissão, pois fundamentaria a religação e a contextualização dos saberes discentes e docentes, favorecendo a compreensão dos conteúdos envolvidos no processo de ensino e aprendizagem (MORIN, 2013).

Além disso, a construção do conhecimento, como referida acima, favoreceria uma aprendizagem significativa entre os alunos. Pois o resgate de saberes previamente aprendidos, unido ao compartilhamento de conhecimentos entre alunos e professores, pode facilitar a aquisição e sedimentação de novas informações, indo além da memorização das mesmas (GADOTTI, 1995).

A perspectiva desse discurso tenciona também uma mediação pedagógica, em que o professor não é o detentor do saber, mas divide e dialoga com o aluno na construção coletiva e colaborativa do saber.

Para Masetto (2012), a mediação pedagógica é entendida como atitude, comportamento do professor que se coloca como facilitador, incentivador ou motivador da aprendizagem. A mediação pedagógica associa-se com a afetividade em práticas pedagógicas, possibilitando um melhor diálogo entre alunos e professores, assim como um ensino e uma aprendizagem colaborativa entre esses atores, podendo culminar em uma gestão participativa de todo o processo educativo.

\section{Integração entre teoria e prática}

A relação teoria e prática carrega uma discussão antiga no âmbito educacional. O que não difere do discurso do grupo pesquisado, pois há o entendimento que ambas precisam estar juntas, dialogando para que enriqueçam o aprendizado do aluno.

Nesse sentido, compreendemos que há a busca por uma rearticulação entre teoria e prática, enfocando a complexidade envolvida no entendimento dos problemas das diversas disciplinas tratadas, levando à centralização do processo de ensino e aprendizagem no aluno, e à facilitação desse processo pelos professores (LEITE, ZABALZA, 2012; MORIN, 2013; FREIRE, 2014).

De acordo com Cunha (2008), a integração entre teoria e prática passa pela retroalimentação entre ambas, diferentemente da utilização conservadora da prática como significação e confirmação da teoria.

\begin{tabular}{|l|c|c|c|c|c|} 
(C) Rev. Inter. Educ. Sup. & Campinas, SP & v.4 & n.2 & p.387-400 & maio/ago. 2018 \\
\hline
\end{tabular}


Em uma visão pautada em atividades pedagógicas inovadoras, a prática seria a fonte da teoria, e não o fim da mesma, além de ser compreendida como multidimensional, requerendo, desse modo, uma intervenção interdisciplinar para a sua compreensão (MORIN, 2013).

\section{O aluno como protagonista da prática pedagógica}

Esse discurso guarda semelhanças com o primeiro discurso síntese (DS 1), principalmente pelo fato de centralizar o processo de ensino e aprendizagem na figura do aluno. Essa centralização recai na transição paradigmática vigente no ensino superior (MORAES, 2012).

No DSC 1, entretanto, o centro do processo de ensino e aprendizagem era dado ao aluno por meio de métodos e técnicas de ensino. Enquanto que neste discurso síntese, o aluno, a partir de si mesmo, assume um papel central, tornando-se protagonista em sua aprendizagem, e por conseguinte, na construção do conhecimento.

Diante desse cenário, Behrens (2005) ressalta a importância da transição paradigmática no ensino superior, que a partir da incorporação de um paradigma educacional emergente nas práticas pedagógicas, estimula o aluno a ser descobridor, transformador e produtor do conhecimento, caracterizando o seu protagonismo no processo de ensino e aprendizagem.

O protagonismo elencado não significa o afastamento entre professores e alunos. Por outro lado, significa o protagonismo conjunto desses dois atores, fator essencial para uma aprendizagem significativa, contribuindo para uma construção colaborativa do saber (GADOTTI, 1995). Assim, professores e alunos teriam uma relação mais horizontalizada e colaborativa, sendo ambos os atores do protagonismo na educação superior.

Propositadamente, encerram-se os discursos com o protagonismo do aluno como forma de inovação pedagógica, e uma contradição. Este que foi o discurso síntese menos frequente entre os docentes pesquisados, conforma-se como um dos itens essenciais na proposição de inovação pedagógica, e na ruptura com modelos conservadores de ensino.

Assim, mesmo que os docentes tenham tido concepções fortemente atreladas à inovação pedagógica, tem-se que notar as fragilidades imbuídas nessas mesmas concepções, para que possam ser discutidos meios de modificação no processo de ensino e aprendizagem, visando adequações às novas formas de aprendizagem, muitas vezes vinculadas às TIC.

Também se deve pensar no fortalecimento da relação acadêmica entre professor, aluno e conteúdos, e de que modo esse fortalecimento pode ser efetuado. Apesar de que já existem

\begin{tabular}{|l|l|l|l|l|l|}
\hline (C) Rev. Inter. Educ. Sup. & Campinas, SP & v.4 & n.2 & p.387-400 & maio/ago. 2018 \\
\hline
\end{tabular}


preocupações concernentes ao compartilhamento de saberes e do próprio planejamento entre professores e alunos, além da busca por integrar teoria e prática neste estudo.

Vislumbra-se que há um caminho traçado para inovação pedagógica no ensino superior, que precisa ser fortalecido e sempre discutido, por todos que formam o processo de ensino e aprendizagem, acreditando na continuidade e na permanente inovação.

Nesse sentido, três aspectos podem ser ressaltados para fortalecer a inovação pedagógica no contexto pesquisado: discutir a inclusão ou o favorecimento da afetividade entre alunos e professor, como forma de mediação pedagógica; integrar outras formas de saber, além daquelas academicamente e cientificamente estruturadas; e avaliar continuamente o processo de ensino e aprendizagem, a fim de manter uma coerência entre os objetivos, métodos e técnicas, e a própria avaliação.

\section{CONSIDERAÇõES FINAIS}

Diante da discussão apresentada nessa investigação, sobre o discurso dos professores universitários e sua concepção de inovação em sua prática docente, compreende-se que a concepção apontada pela maioria dos professores surgiu em relação ao ensino que estimule a aprendizagem do aluno.

Esse resultado sinaliza uma nova demanda na forma de ensinar apontada pelos docentes, que favorece o aluno como o sujeito principal no processo de ensino e aprendizagem, provocando uma nova dinâmica nesse processo. Vale ressaltar, o estímulo aos alunos para serem autônomos na construção e na produção do conhecimento.

Contudo, esse achado contribui para a reflexão sobre a importância de estratégias didáticas inovadoras no ensino superior, que é um campo mais resistente a mudanças, por uma ligação secular a concepções de ciência e educação mais conservadoras.

Nesse sentido, a compreensão da concepção sobre inovação pedagógica no ensino superior, busca motivar os professores universitários a uma formação docente mais significativa e humanizadora, a fim de se provocar uma ruptura paradigmática, gerando uma demanda na universidade que vá além da formação discente, recaindo na formação docente, que será facilitador de formação no ciclo da educação universitária. 


\section{REFERÊNCIAS}

ALMEIDA, Márcio José et al. Implantação das Diretrizes Curriculares Nacionais na graduação em medicina no Paraná. Revista Brasileira de Educação Médica, v. 31, n. 2, p. 156-165, 2007.

BEHRENS, Marilda Aparecida. O paradigma emergente e a prática pedagógica. Petrópolis: Vozes, 2005.

CANGUILHEM, Georges. O normal e o patológico. 7. ed. Rio de Janeiro: Forense Universitária, 2011.

CRESWELL, John. W. Investigação qualitativa e projeto de pesquisa. 3. ed. Porto Alegre: Penso, 2014.

CUNHA, Maria Isabel da. Inovações pedagógicas: o desafio da reconfiguração de saberes na docência universitária. Universidade de São Paulo: Pró-Reitoria de Graduação, 2008.

DELORS, Jacques et al. Educação: um tesouro a descobrir. São Paulo: Cortez; Brasília: UNESCO, 1998.

DIAS SOBRINHO, José. Dilemas da educação superior no mundo globalizado: sociedade do conhecimento ou economia do conhecimento? São Paulo: Casa do psicólogo, 2005.

FLECK, Ludwik. Gênese e desenvolvimento de um fato científico. Belo Horizonte: Fabrefactum, 2010.

FOUCAULT, Michel. O nascimento da clínica. 6. ed. Rio de Janeiro: Forense Universitária, 2006.

FOUCAULT, Michel. Microfísica do poder. 28. ed. Rio de Janeiro: Paz e Terra, 2014.

FREIRE, Paulo. Pedagogia da autonomia: saberes necessários à prática educativa. 49. ed. Rio de Janeiro: Paz e Terra, 2014.

FREINET, Célestin. Pedagogia do bom senso. 7. ed. São Paulo: Martins Fontes, 2004.

GADOTTI, Moacir. Concepção dialética da educação: um estudo introdutório. 9. ed. São Paulo: Cortez, 1995.

KENSKI, Vani. Moreira. Educação e tecnologia: o novo ritmo da informação. Campinas: Papirus, 2012. 
LEFÈVRE, Fernando; LEFÈVRE, Ana Maria Cavalcanti. O discurso do sujeito coletivo: um novo enfoque em pesquisa qualitativa (desdobramentos). 2. ed. Caxias do Sul: Educs, 2005.

LEITE, Carlinda; ZABALZA, Miguel. Ensino superior: inovação e qualidade na docência. Porto: Centro de Investigação e Intervenção Educativas, 2012.

LÉVY, Pierre. As tecnologias da inteligência: o futuro do pensamento na era da informática. 2. ed. São Paulo: Editora 34, 2010.

MASETTO, Marcos Tarciso. Docência na universidade. 11. ed. Campinas: Papirus, 2012.

MORAES, Maria Cândida. O paradigma educacional emergente. 16. ed. Campinas: Papirus, 2012.

MORAN, José Manuel; MASETTO, Marcos T.; BEHRENS, Marilda Aparecida. Novas tecnologias e mediação pedagógica. 21. ed. Campinas: Papirus, 2013.

MORIN, Edgar. A cabeça bem-feita: repensar a reforma, reformar o pensamento. 20. ed. Rio de Janeiro: Bertrand Brasil, 2012.

MORIN, Edgar. A religação dos saberes: o desafio do século XXI. 11. ed. Rio de Janeiro: Bertrand Brasil, 2013.

SALES, Shirlei Rezende; LEAL, Rafaela Esteves Godinho. Práticas pedagógicas inovadoras na formação docente: ciborguização do currículo do curso de pedagogia. Revista

Internacional de Ensino Superior, v. 4, n. 1, p. 6-24, jan./abr. 2018.

SANTOS, Boaventura de Sousa. Um discurso sobre as ciências. 16. ed. Porto: Edições Afrontamento, 2010.

SANTOS, Boaventura de Sousa. A crítica da razão indolente: contra o desperdício da experiência. 8. ed. São Paulo: Cortez, v. 1, 2011.

\section{Sobre os Autores}

\section{${ }_{1}^{1}$ Raul Araújo}

E-mail: raulamaralaraujo@gmail.com / ORCID: http://orcid.org/0000-0002-1318-3534

Universidade Federal de Pernambuco - Brasil

Doutorando do Programa de Pós-Graduação em Saúde da Criança e do Adolescente pela Universidade Federal de Pernambuco [UFPE].

\section{${ }^{2}$ Rosalie Belian}

E-mail: rosalie.belian@gmail.com / ORCID: http://orcid.org/0000-0002-3978-4936

Universidade Federal de Pernambuco - Brasil

Docente da Universidade Federal de Pernambuco [UFPE]. 